\title{
LXXXV. The bakerian lecture. an account of some new analytical researches on the nature of certain bodies, particularly the alkalies, phosphorus, sulphur, carbonaceous matter, and the acids hitherto undecomposed; with some general observations on chemical theory
}

\author{
Humphry Davy Esq. Sec. R.S. F.R.S. M.R.I.A.
}

To cite this article: Humphry Davy Esq. Sec. R.S. F.R.S. M.R.I.A. (1809) LXXXV. The bakerian lecture. an account of some new analytical researches on the nature of certain bodies, particularly the alkalies, phosphorus, sulphur, carbonaceous matter, and the acids hitherto undecomposed; with some general observations on chemical theory, Philosophical Magazine Series 1, 33:134, 479-488, DOI: 10.1080/14786440908562908

To link to this article: http://dx.doi.org/10.1080/14786440908562908

Published online: 18 May 2009.

Submit your article to this journal $\sqsubset$

Џll Article views: 2 
LXXXV. The Bakerian Lecture. An Account of some new analytical Researches on the Nature of certain Bodies, particularly the Alkalies, Phosthorus, Sulphur, Carbonaceous Matter, and the Acids hitherto undecomposed; with some general Observations on Chemical Theory. By Huмрнич Davy, Esq., Sec. R.S., F.R.S. Edin., and M.R.I.A.*

\section{Introduction.}

$I_{\mathrm{N}}$ the following pages, I shall do myself the honour of laying before the Royal Society, an account of the results of th different experiments, made with the hopes of extending our knowledge of the principles of bodies by the new powers and methods arising from the applications of electricity to chemistry, some of which have been long in progress, and others of which have been instiruted since their last session.

The objects wirich have principally occupied my attention, are the elementary matter of ammonia, the nature of phosphorus, sulphur, charcoal, and the diamond, and the constituents of the boracic, fluoric, and muriatic acids.

Amongst the numerous processes of decomposition, which I have attempted, naany have been successful; and from those which have failed, some new phænomena have usually resulted which may possibly serve as guides in future inquiries. On this account, I shall keep back no part of the investigaiton, and I shall trust to the candour of the Suciety for an excuse for its imperfection.

The more approaches are made in chemical inquiries towards the refined analysis of bodies, the greater are the obstacles which present themselves, and the less perfect the results.

All the difficulties which occur in analysing a body, are direct proofs of the energy of attraction of its constituent parts. In the play of affinities with respect to secondary compounds even, it rarely occurs that any perfectly pure or unmixed substance is obtained; and the principle applies still more strongly to primary combinations.

The first methods of experimenting on new objects like-

* Fron Philosophical ranactiogs for 1809. Part I. 
wise are necessarily imperfect; novel instruments are demanded, the use of which is only gradually acquired, and a number of experiments of the same kind must be made, before one is obtained from which correct data for conclusions can be drawn.

\section{Experiments on the Action of Polassium on Ammonia, and Observations on the Nature of these two Bodies.}

In the Bakerian lecture, which $I$ had the honour of reading before the Society, November 19, 1807, I mentioned that, in heating potassium strongly in ammonia, I found that there was a cousiderable increase of volume of the gas, that hydrogen and nitrogen were produred, and that the potassium appeared to be oxidated; but this experiment, as I had not been able to examine the residuum with accuracy, I did not publish. I stated it as an evidence, which I intended to pursue more fully, of the existence of oxygen in ammonia.

In a paper read before the Royal Society last June, which they have done me the honour of printing, I have given an account of various experiments on the amalgam from ammonia, discovered by Messrs. Berzelius and Pontin, and in a note attached to this communication I ventured to controvert an opinion of MM. Gay Lussac and Thenard, with respect to the agency of potassium and ammonia, even on their own statement of facts, as detailed in the Moniteur for May 27, 1808:

The general obscurity belonging to these refined objects of research, their importance and connection with the whole of chemical theory, have induced me since that lime to apply to them no inconsiderable degree of labour and attention; and the results of $\mathrm{my}$ inquiries will, I trust, be found not only to confirm my former conclusions; but likewise to offer some novel views.

In the first of these series of operations on the action of potassium on ammonia, I used retorts of the green glass; I then, suspecting oxygen might be derived from the metallic oxides in the green glass, employed retorts of plate glass; and last of all, I fastened the potassium upon trays of pla. tina, or iron, which were introduced into the glass retorts 
furnished with stop cocks. These retorts were exhausted by an excellent air pump, they were filled with hydrogen, exhausted a second time, and then filled with ammonia from an appropriate mercurial gas holder*. In this way the gas was operated upon in a high degree of purity, which was always ascertained; and all the operations performed out of the contact of mercury, water, or any substances that could interfere with the results.

I at first employed potassium procured by electricity; but I soon substituted for it the metal obtained by the action of ignited iron upon potash, in the happy method discovered by MM. Gay Lussac and Thenard, finding that it gave the same results, and could be obtained of an uniform quality $\uparrow$, and in infinitely larger quantities, and with much less labour and expense.

When ammonia is brought in contact with about twice its weight of potassium at common temperatures, the metal loses its lustre and becomes white, there is a slight diminution in the volume of the gas; but no other effects are produced. The white crust examined proves to be potash, and the ammonia is found to contain a small quantity of hydrogen, usually not more than equal in volume to the metal. On heating the potassium in the gas, by means of a spirit lamp applied to the bottom of the retort, the colour of the crust is seen to change from white to a bright azure, and this gradually passes through shades of bright blue and green into dark olive. The crust and the metal then fuse together; there is a considerable effervescence, and the crust passing

\footnotetext{
* A representation of the instruments will be given in the next Number of our Magazine.
}

+ When the potash used for procuring potassium in this operation was very pure, and the iron tursings likewise very pure and clean, and the whole apparatus free from any foreign matters, the metal produced differed very little, in its properties, from that obtained by the Voltaic battery. Its lustre, ductility, and inflammability were similar. Its point of fusion and specific gravity were, however, a little higher, it requiring nearly $130^{\circ}$ of Fahrenheit to render it perfectly fluid, and being to water as 7960 to 10000 , at $60^{\circ}$ Fahrenheit. This $I$ am inclined to attribute to its containing a minute proportion of iron.

Vol. 33. No. 134. June 1809.

$\mathrm{H} \mathrm{h}$

off 
off to the sides, suffers the brilliant surface of the potassium to appear. When the potassium is cooled in this state, it is again covered with the white crust. By heating a second time, it swells considerably, becomes porous, and appears crystallized, and of a beautiful azure tint; the same series of phænomena, as those before described, occur in a continuation of the process, and it is finally entirely converted into the dark olive-coloured substance.

In this operation, as has been stated by MM. Gay Lussac and Thenard, a gas which gives the same diminution by detonation with oxygen as hydrogen is evolved, and ammonia disappears.

The proportion of the ammonia which loses its elastic form, as I have found by numerous trials, varies according as the gas employed contains more or less moisture.

Thus eight grains of potassium, during its conversion into the olive-coloured substance, in ammonia saturated with water at $63^{\circ}$ Fahrenheit, and under a pressure equal to that of 29.8 inches of mercury, had caused the disappearance of twelve cubical inches and a half of ammonia; but the same quantity of metal acted upon under similar circumstances, except that the ammonia had been deprived of as much moisture as possible by exposure for two days to potash that had been ignited, occasioned a disappearance of sixteen $\mathrm{cu}$. bical inches of the volatile alkali.

Whatever be the degree of moisture of the gas, the quantities of inflammable gas generated bave always appeared to me to be equal for equal quantities of metal. MM. Gay Lussac and Thenard are said to have stated, that the proportions in their experiment were the same as would have resulted from the action of water upon potassium. In my trials, they have been rather less. Thus, in an experiment conducted with every possible attention to accuracy of manipulation, eight grains of potassium generated, by their operation upon water, eight cubical inches and a half of hydrogen gas : and eight grains from the same mass, by their action upon ammonia, produced eight cubical inches and one-eighth of inflammable gas. This difference is inconsiderable; yet I have always 
always found it to exist, even in cases where the ammonia has been in great excess, and every part of the metal apparently converted into the slive-coloured substance.

No other account of the experiments of MM. Gay Lussac and Thenard has, I believe, as yet heen received in this country, except that in the Moniteur already referred to; and in this no mention is made of the properties of the substance produced by the action of ammonia on potassium. Having examined them minutely and found them curious, I shall generally describe them.

1. It is crystallized, and presents irregular facets, which are extremely dark, and in colour and lustre not unlike the protoxide of iron; it is opaque when examined in large masses, but is semi-transparent in thin films, and appears of a bright brown colour by transmitted light.

2. It is fusible at a heat a little above that of boiling water, and if heated much higher, emits globules of gas.

3. It appears to be considerably heavier than water, for it sinks rapidly in oil of sassafras.

4. It is a non-conductor of electricity.

5. When it is melted in oxygen gas, it burns with great vividness, emitting bright sparks. Oxygen is absorbed, nitrogen is emitted, and potash, which from its great fusibility seems to contain water, is formed.

6 . When brought in contact with water, it acts upon it with much energy, produces heat, and often inflammation, and evolves ammonia. When thrown upon water, it disappears with a hissing noise, and globules from it often move in a state of ignition upon the surface of the water. It rapidly effervesces and deliquesces in air, but can be preserved under naphtha, in which, however, it softens slowly, and seems partially to dissolve. When it is plunged under water filling an inverted jar, by means of a proper tube, it disappears instantly with effervescence, and the non-absorbable elastic fluid liberated is found to be hydrogen gas.

By far the greatest part of the ponderable matter of the ammonia, that disappears in the experiment of its action upon potassium, evidently exists in the dark fusible product. On weighing a tray containing six grains of potassium, be$\mathrm{Hh} 2$ 
fore and after the process, the volatile alkali employed having been very dry, I found that it had increased more than two grains; the rapidity with which the product acts upon moisture, prevented me from determining the point with great minuteness ; but I doubt not, that the weight of the olivecoloured substance and of the hydrogen disengaged precisely equals the weight of the potassium, and ammonia consumed.

MM. Gay Lussac and Thenard* are said to have procured from the fusible substance, by the application of a strong heat, two fifths of the quantity of ammonia that had disappeared in their first process, and a quantity of hydrogen and nitrogen in the proportions in which they exist in ammonia, equal to one fifth more.

My results have been very different, and the reasons will, I trust, be immediately obvious.

When the retort containing the fusible substance is exhausted, filled with hydrogen and exhausted a second time, and heat gradually applied, the substance soon fuses, effervesces, and, as the heat increases, gives off a considerable quantity of elastic fluid, and becomes at length, when the temperature approaches nearly to dull redness, a dark gray solid, which, by a continuance of this degree of heat, does not undergo any alteration.

In an experiment, in which eight grains of potassium had absorbed sixteen cubical inches of well dried ammonia in a glass retort, the fusible substance gave off twelve cubical inches and half of gas, by being heated nearly to redness, and this gas analysed, was found to consist of three quarters of a cubical inch of ammonia, and the remainder of elastic fluids, which, when mixed with oxygen gas in the proportion of $6 \frac{\mathrm{I}}{2}$ to 6 , and acted upon by the electric spark, diminished to $5 \frac{\mathrm{I}}{2}$. The temperature of the atmosphere, in this process, was $57^{\circ}$ Fahrenheit, and the pressure equalled that of 30.1 inches of mercury.

In a similar experiment, in which the platina tray containing the fusible substance was heated in a polished iron tube,

* No notice is taken of the apparatus used by MM. Gay Lussac and Thenard in the Moniteur; but, from the tenour of the details, it seems that they must have operated in glass vessels in the way heretofore adopted over mercury.

filled 
filled with hydrogen gas, and connected with a pneumatic apparatus containing very dry mercury, the quantity of elastic fuid given off, all the corrections being made, equalled thirteen cubical inches and three quarters, and of these a cubical inch was ammonia; and the residual gas, and the gas introduced into the tube being accounted for, it appeared that the elastic fluid generated, destructible by detonation with oxygen, was to the indestructible elastic fluid, as 2.5 to 1 .

In this process, the heat applied approached to the dull red heat. The mercury, in the thermometer, stood at $62^{\circ}$ Fahrenheit, and that in the barometer at $30 \cdot 3$ inches.

In varions experiments on different quantities of the fusible substance, in some of which the heat was applied to the tray in the green glass retort, and in others, after it had been introduced into the iron tube; and in which the temperature was sometimes raised slowly and sometimes quickly, the comparative results were so near these that $I$ have detailed, as to render any statement of them superfluous.

A little more ammonia, and rather a larger proportion of inflammable gas*, were in all instances evolved when the iron tube was used, which I am inclined to attribute to the following circumstances. When the tray was brought through the atmosphere to be introduced into the iron tube, the fusible substance absorbed a small quantity of moisture from the air, which is connected with the production of ammonia. And in the process of heating in the retort, the green glass was blackened, and I found that it contained a very small quantity of the oxides of lead and iron, which must have caused the disappearance of a small quantity of hydrogen.

MM. Gay Lussac and Thenard, it appears from the statement, had brought the fusible substance in contact with mercury, which must have given to it some moisture; and whenever this is the case, it furnishes by heat variable quantities of ammonia. In one instance, in which I heated the fusible substance from nine grains of potassium, in a

* The average of six experiments made in a tube of iron, is 244 of inflammable gas to 1 of uninflammable. The average of three made in green glass retorts, is 2.3 to 1 . 
retort that had been filled with mercury in its common state of dryness, I obtained seren cubical inches of ammonia as the first product; and in another experiment which had been made with eight grains, and in which moisture was purposely introduced, I obtained nearly nine cubical inches of ammonia, and only four of the mixed gases.

I am inclined to believe, that if moisture could be introduced only in the proper proportion, the quantity of ammonia generated, would be exactly equal to that which disappeared in the first process.

This idea is confirmed by the trials which I have made, by heating the fusible substance with polash, containing its water of crystallization, and muriate of lime partially dried*.

In both these cases, ammonia was generated with great rapidity, and no other gas, but a minute quantity of inflammable gas, evolved, which was condensed by detonation with oxygen with the same phænomena as pure hydrogen.

In one instance, in which thirteen cubical inches of ammonia had disappeared, I obtained nearly eleven and three quarters by the agency of the water of the potash ; the quantity of inflammable gas generated, was less than four tenths of a cubical inch.

In another, in which fourteen cubical inches had been absorbed, I procured by the operation of the moisture of muriate of lime, nearly eleven cubical inches of volatile alkali, and half a cubical inch of inflammable gas; and the differences, there is every reason to believe, were owing to an excess of water in the salts, by which snme of the gas was ahsorbed.

Whenever, in experiments on the fusible substance, it has been procured from ammonia saturated with moisture, I have always found that more ammonia is generated from it by mere heat; and the general tenour of the experiments inclines me to believe, that the small quantity, produced in experi-

* If water, in its common form, is brought in contact with the fusible substance, it is impossible to regulate the quantity, so as to gain conclusive results, and a very slight excess of water causes the disappearance of a very large quantity of the ammonia generated. In potash and muriate of lime, in certain states of dryness, the water is too strongly attracted by the saline matter to be given off, except for the purpose of generating the ammonia.

ments 
ments performed in vacuo, is owing to the small quantity of moisture furnished by the hydrogen gas introduced, and that the fusible substance, heated out of the presence of moisture, is incapable of producing volatile alkali.

MM. Gay Lussac and Thenard, it is stated, after having obtained three fifths of the ammonia or its elements that had disappeared in their experiment, by heating the product, procured the remaining two fifths, hy adding water to the residuum, which after this operation was found to be potash. No notice is taken of the properties of this residuum, which, as the details seem to relate to a single experiment, probably was not examined; nor, as moisture was present at the beginning of their operations, could any accurate knowledge of its nature have been gained.

I have made the residuum of the fusible substance after it has been exposed to a dull red heat, out of the contact of moisture, an object of particular study, and I shall detail its general properties.

It was examined under naphtha, as it is instantly destroyed by the contact of air.

l. Its colour is black, and its lustre not much inferior to that of plumbago.

2. It is opaque even in the thinnest films.

3. It is very brittle, and affords a deep gray powder.

4. It is a conductor of electricity.

5. It does not fuse at a low red heat, and when raised to this temperature, in contact with plate glass, it blackens the glass, and a grayish sublimate rises from it, which likewise blackens the glass.

6. When exposed to air at common temperatures, it usually takes fire immediately, and burns with a deep red light.

7. When it is acted upon by water, it heats, effervesces most violently, and evolves volatile alkali, leaving behind nothing but potash. When the process is conducted under water, a little inflammable gas is found to be generated. A residuum of eight grains giving in all cases about ${ }_{120}^{20}$ of a cubical inch.

8. It has no action upon quicksilver.

9. It combines with sulphur and phosphorus by heat, $\mathrm{H} \mathrm{h} 4$ 
without any vividness of effect, and the compounds are highly inflammable, and emit ammonia, and the one phosphuretted and the other sulphuretted hydrogen gas, by the action of water.

[T'a be continued.]

IXXXVI. On the Agency of Electricity on Animal Secretions. By Wm. H. Wollaston, M.D., Sec. R.S.

A $\mathrm{T}$ the time when Mr. Davy first communicated to me bis important experiments on the separation and transfer of chemical agents by means of the Voltaic apparatus, which was in the autumn of 1806 , I was forcibly struck with the probability that animal secretions were affected by the agency of a similar electric power; since the existence of this power in some auimals was fully proved by the phænomena of the Torpedo, and of the Gymnotus Electricus; and since the universal prevalence of similar powers of lower intensity in other animals was rendered highly probable by the extreme suddenness with which the nervous influence is communicated from one part of the living system to another.

And though the separation of chemical agents, as well as their transfer to a distance, and their transition through solids, and through fluids which might be expected to oppose their progress, had not then been effected but by powerful batteries; yet it appeared highly probable that the weakest electric energies might be capable of producing the same effects, though more slowly in proportion to the weakness of the powers employed.

I accordingly at that time made an experiment for clucidating this hypothesis, and communicated it to $\mathrm{Mr}$. Davy and to others of my friends. But though it was conclusive with regard to the sufficiency of very feeble powers, it did not appear deserving of publication, until I could adduce some evidence of the actual employment of such means in the animal œconmy.

As I am not accustomed to making experiments on living animals, 